\title{
Lumbo-Sacral Radiculopathy Induced by Radiation
}

\author{
E. M. ASHENHURST, G. R. C. QUARTEY AND A. STARREVELD
}

SUMMARY: Two patients had lumbosacral radiculopathy following radiation treatment of cancer. Twenty previously reported cases were similar. The clinical picture is one of progressive motor and sensory loss in the legs, usually appearing within a year after radiation, but sometimes delayed up to several years. Experimental studies quoted indicate greater vulnerability of peripheral nerves to ionizing radiation than has been previously recognized. Lumbo-sacral radiculopathy is readily produced in the experimental animal (rat) and affords an experimental model closely resembling the human cases reported.

RESUMÉ: Deux patients ont manifesté une radiculopathie lombo-sacrée à la suite d'une radiothérapie pour cancer. Les vingt cas précédemment publiés sont semblables: ainsi le tableau clinique est-il marqué par une perte progressive des fonctions motrices et sensitives aux jambes apparaissant environ un an après l'irradiation, mais parfois tardant de plusieurs années. Les études expérimentales également citées montrent qu'il existe une susceptibilité aux radiations ionisantes des nerfs périphériques plus importante qu'on ne l'avait d'abord cru. La radiculopathie lombo-sacrée peut être facilement produite chez l'animal expérimental (rat) et permet l'étude d'un modèle expérimental semblable aux cas humains rapportés.

From the Division of Neurology, University of Saskatchewan and University Hospital, Saskatoon.

Reprint requests to: Dr. E. M. Ashenhurst, Division of Neurology, University Hospital, Saskatoon, Saskatchewan S7N 0W8.

\section{INTRODUCTION}

Peripheral neuropathy as a delayed complication of radiotherapy is considered a rarity. Observations on the effects of jonizing radiation on peripheral nerves of experimental animals have been contradictory and incomplete. Most observers stress the extreme resistance of peripheral nerves to radiation. On the other hand, obvious delayed degeneration of spinal nerves following doses of $x$-rays close to the clinical range has been reported (Linder, 1959; Innes, 1967). On the clinical side, neuropathies of the brachial plexus and cranial nerves following radiation for carcinoma of the breast, head and neck and Hodgkin's disease have all been extensively documented (Stoll and Andrews, 1966; Maruyama et al., 1967; Cheng et al., 1975; Bataini et al., 1974; Shukovsky and Fletcher, 1972). The effects of radiation therapy on the lumbo-sacral plexus have been described only rarely (Greenfield and Stark, 1948; Klaua, 1974; Friedman, 1954; Maier et al., 1969). We describe delayed neuropathy of the lumbo-sacral plexus in two patients, treated with telecobalt radiation for carcinomas of the bladder and cervix.

Case 1. This 60-year-old man had intermittent painless hematuria for one month in 1964. Cystoscopy revealed "resolving hemorrhagic cystitis". In January, 1965, biopsy was done and a diagnosis of transitional cell carcinoma of the urinary bladder was made. He was treated by radiation receiving 6,750 rads in 24 treatments. (Details of this follow the case report.)

He was admitted to hospital in October, 1965 with symptoms of bowel obstruction, shown at laparotomy to be due to pelvic fib- rosis and stricture of the rectum. A terminal colostomy was made. There was no evidence of cancer in the rectosigmoid area.

In 1969, four years after completion of radiotherapy, he complained of numbness of the soles of his feet; this subsequently spread to his knees. There was also severe aching pain in the feet. Over the next three years he complained of progressive weakness of the leg muscles, most severe distally. He had continued to walk in spite of bilateral foot drop. In October, 1972, he was admitted to hospital for neurological evaluation.

General physical examination showed no abnormality. There was no evidence of recurrence of the bladder carcinoma. His colostomy was functioning well. Neurological abnormalities were confined to the legs with findings somewhat more severe on the left side. There was moderate weakness of flexion and adduction and slight weakness of abduction and extension at the hips. Knee flexion was weak but extension preserved. Bilateral foot-drop was evident. Plantar flexion at the ankles was almost normal. The knee and ankle jerks were absent. There was impairment of sensation distally, light touch and pain sensation were impaired to the knees and vibration and joint-position sense were lost in the feet.

Radiograms of the lumbo-sacral spine and pelvis, lumbar myelogram, CSF examination, glucose tolerance test and Schilling test were all normal. EMG and nerve conduction studies indicated proximal nerve involvement.

Reviewed in September, 1975, he described further slight worsening of his symptoms. He continued to walk with the use of leg braces. There was no evidence of recurrence of the bladder carcinoma. Neurologically, 
he exhibited severe wasting of both legs, the left more than the right. Fasciculations were noted in the anterior right thigh muscles. There was good strength in the abdominal muscles. There was weakness of all the leg muscles. No voluntary movement was noted in the left hip abductors and knee flexors. There was complete bilateral foot-drop. Muscle stretch reflexes were absent in both legs. Sensory testing revealed distal hypalgesia to the mid-calf on the right side and to mid-thigh on the left. Vibration sense was absent below the anterior superior iliac spines. Joint-position sense was absent in the feet and impaired at the knees.

Details of Radiation Therapy: Between December 29, 1964, and February 3, 1965, a radical course of radiotherapy was given. The tumor dose was 6,750 rads. Two pairs of parallel and opposing fields were used. The anterior and posterior fields measured $10 \times 15 \mathrm{cms}$. and the lateral fields $10 \times 10 \mathrm{cms}$. Each pair of fields was treated on alternate days. The total number of treatment days was 24 over a total elapsed period of 36 days. On 14 of 24 days treatments were given with $22 \mathrm{MEV}$ Betatron. On the remaining 10 days the "Saskatoon" cobalt-60 unit was used.

The total tumor dose of 6,750 rads over 24 days is rather high. A more usual dose would be 6,000 to 6,500 rads over a total time period of 5 to 6 weeks, in which case somewhat smaller fields are used for at least part of the time.

Case 2. In July, 1967, this woman, aged 48, had a routine Pap smear done, following which a biopsy of the cervix was taken. A Stage II squamous cell carcinoma of the cervix was found. Physical examination showed no abnormality. First and second stage Manchester radium implantations were made and subsequently a three-week course of deep $x$-ray therapy to the parametria. (Details given after case report.)

In December, 1973, she was seen in the neurological clinic. She first had problems with her legs six months after completing the course of deep x-ray therapy. These consisted of burning and tingling sensations in the feet along with generalized "discomfort" of the legs. Her paresthesias were increased by walking. Symptoms had slowly progressed until her presentation at the clinic. There had been no sphincter disturbance.

Examination revealed a wellorientated co-operative woman, who gave a good history. The general physical examination showed no abnormalities. Neurologically, the abnormal findings were confined to the legs. There was slight weakness of dorsiflexion and eversion at the ankles, the left more so than the right. The muscle stretch reflexes were absent at both ankles and at the left knee. The right knee jerk could only be obtained with reinforcement. Pain sensation was impaired in a stocking distribution to about midcalf regions bilaterally. Touch and joint-position sense were also slightly depressed in the feet.

When reviewed in May, 1975, she said her troublesome paresthesias had persisted and she had also noted some increase in the weakness of the legs, the left more so than the right.

Neurological examination revealed moderately severe weakness of all movements at the left ankle and mild to moderate weakness of all movements at the right ankle. All muscles tested in the legs were weak to some degree. No muscle stretch reflexes were obtained. The right knee jerk had previously been obtained with reinforcement. Pain and touch sensation were impaired as before to mid-calf bilaterally. In addition, there was marked reduction of joint-position sense in the toes and at the ankles, plus reduction of vibratory sense throughout both legs.

Several investigations, including serum B 12 , serum T4, thoracic and lumbar spine $\mathrm{x}$-rays were normal. EMG and nerve conduction studies revealed decreased conduction potentials of the muscles tested, indicating a diffuse moderate neuropathy in the legs.

When reviewed in September, 1975, physical findings were similar to those recorded in May of the same year.

Details of Radiation Therapy: On July 25 and August 1, 1967, intracavitary radium insertions were carried out using the Manchester technique. On each occasion $2 \times 13.3$ and $1 \times 10 \mathrm{mgm}$ radium tubes were inserted into the uterine cavity while two medium-sized vaginal ovoids, each with $2 \times 13.3 \mathrm{mgm}$ radium tubes, were placed in the vaginal fornices separated by spacer. Ionization probe readings were taken in the bladder and in the rectum. Intracavitary radiation was given for 54 hours after the first insertion and for 56 hours after the second insertion.

From August 8 to August 25, 1967, inclusive, a course of external radiation to the parametria was given with the "Saskatoon" cobalt-60 therapy unit delivering 4,000 rads tumor dose to $15 \times 15 \mathrm{~cm}$ parallel and opposing anterior and posterior pelvic fields with midline shielding. The total elapsed time period was 16 days, the number of fractions being 14 .

The total dosage in rads from intracavitary radiation alone was computed to be 8,190 rads to point $A$ on the left side and 5,320 rads to point $\mathrm{A}$ on the right side. The total dose for intracavitary radiation to point $B$ was 2,760 rads on the left side and 1,900 on the right side. Point $\mathrm{A}$ was taken in the paracervical triangle as defined by Todd and Meredith, 1938: $2 \mathrm{cms}$ lateral to the central canal of the uterus and $2 \mathrm{cms}$ up from the mucous membrane of the lateral fornix in the axis of the uterus. Point B is taken $3 \mathrm{~cm}$ laterally of $A$. Adding the amount of external radiation $(4,000$ rads tumor dose computed at mid-pelvis) to the amount of radiation to point $B$ on the left and right side, a total of 6,750 rads was given to the left pelvic wall and a total of 5,900 to the right pelvic wall.

Though the total dose to the left pelvis was computed to be in the same range as for Case 1, we have to note the fact that she had both intracavitary radiation and external radiation. The biological effects of these two types of radiation are rather difficult to delineate and do 


\begin{tabular}{lccrr} 
& $\begin{array}{c}\text { L pelvic wall } \\
\text { (Point B Left) }\end{array}$ & $\begin{array}{c}\text { R pelvic wall } \\
\text { (Point B Right) }\end{array}$ & A Left & A Right \\
\hline Intracavitary radiation & 2,760 rads & 1.900 rads & 8.190 rads & 5,320 rads \\
External radiation & 4,000 rads & 4,000 rads & Shielded & Shielded \\
\hline Total & 6.760 rads & 5,900 rads & $\mathbf{8 , 1 9 0 ~ r a d s}$ & 5,320 rads
\end{tabular}

not amount to a simple summation as has been done here. It is possible that the dose to certain nerve trunks situated near the vicinity of the intracavitary radiation axis exceeded the mentioned total since according to the computed data a much higher dose was given to the left side. The asymmetry in her neurological signs was pronounced and would be in accord with the above considerations.

\section{DISCUSSION}

A. Experimental Aspects. Peripheral nerve tissue is largely non-mitotic so that radiation damage is likely to become manifest only if some injury stimulates the component cells into mitotic activity. The experiments of Cavanagh (1968) support this concept. He crushed the sciatic nerves of rats shortly after doses of 200 to 2,000 rads had been given at a dose rate of 100 rads per minute. At seven days there was a slight but significant reduction in the total cell population following 200 rads, a greater reduction after 500 rads, and after 1,000 rads the cell population of the nerves was 81.4 percent of the control population. 2,000 rads caused further reduction to 70.9 percent of normal. Mitotic rates showed a comparable decline with dose. At 14 days after 200 rads the nuclear population lay within the range of the unradiated nerves and the mitotic rates were at comparable levels. With 1,000 rads and even more so with 2,000 rads a serious failure of proliferation became apparent. Pathological changes were apparent in Schwann cells, endoneurial fibroblasts, vascular cells and, occasionally, perineurial cells. As far as evidence of repair of irradiated cells with passage of time was concerned, no difference was found in repair mechanisms of crushed nerves at three weeks or at nine months.

Bradley et al. (1977), studied the delayed effects of irradiation of the thoracic and lumbar spinal cord and cauda equina in rats. The rats were given 3,500 rads of $x$-radiation in a single dose while breathing oxygen at one atmosphere pressure. The changes seen in the thoracic series were those of myelopathy, sometimes progressing to total transverse necrotic myelopathy. In no animal was damage detectable in the thoracic spinal roots. Similar findings have been reported by others. In striking contrast, the rats in the lumbar series showed either no evidence of spinal cord damage (more than $50 \%$ ) or evidence of a minor degree of myelopathy. The anterior and posterior nerve roots were severely damaged. "The conclusion is inescapable that the radiculopathy and not the myelopathy was responsible for the clinical signs in the lumbar series" (Bradley et al., 1977). The cauda equina series showed essentially the same clinical signs and pathological changes in the roots as the lumbar series.

In the light of these experimental findings the authors suggested that attention be given to the spinal roots in the pathological investigation of patients with radiation myelopathy, particularly where the lumbo-sacral cord had been irradiated.

B. Clinical Aspects. Maier et al. (1969) summarized the findings in 15 patients treated by irradiation for malignant germ-cell tumors of the testicle. In most patients the radiation fields included the inguinal and iliac lymph nodes on the involved side as well as the para-aortic lymph nodes to the level of the diaphragm. Three of these patients had been reported previously by Greenfield and Stark (1948) and another six by Friedman (1954). In every patient the neurological abnormalities consisted of lower motor neuron weakness of the legs together with loss of deep reflexes and some fasciculation. Although cystometrograms demonstrated bladder atonicity in some cases, loss of bladder or rectal sphincter function was not evident even in the two patients with paraplegia. A remarkable feature was the absence of sensory loss. The clinical findings are summarized in Table I (cases 1-15), along with those of other reported cases. While these patients have been reported as radiation myelitis of the dorso-lumbar spine, the authors (Maier et al., 1969) recognize an alternative interpretation. "From the clinical findings it is possible that the site of injury is in the lumbar and sacral nerve plexuses instead of or in addition to the spinal cord." We believe that the purely lower motor signs, the absence of long-tract signs, the frequent asymmetry and the lack of sphincter disturbance in these patients all speak strongly for involvement of the lumbo-sacral plaxus rather than spinal cord. There was no pathological examination of the spinal cord or nerve roots in these or other reported cases.

Klaua (1974) reported five patients (from a series of 430) who had telecobalt radiation of the abdominal area and developed lumbo-sacral plexus lesions. The symptoms developed between two and 14 months after completion of radiation treatment. They tended to be chronic and progressive, sometimes with stepwise relapses. Autopsies had been done on two patients. Retroperitoneal fibrosis was seen in both cases. No examination of the spinal cord or nerve roots was reported.

In considering the present and previously reported cases, certain characteristics of radiation induced damage to the lumbo-sacral plexus can be identified. Lumbo-sacral neuropathy may follow irradiation of the abdominal cavity for the treatment of cancer. The incidence of the complication appears to be small ( 5 patients in one series of 430 for an incidence of 1 percent). The dose of radiation to the lumbar spinal cord has varied between a high of 5,680 rads and a low of 1,700 rads. If the dose is estimated for the posterior pelvic wall somewhat higher figures are obtained. The interval between irradiation and the occurrence of neuropathy is variable. In 15 of 22 
TABLE I

Reported Cases of Lumbo-Sacral Neuropathy Following Radiation

\begin{tabular}{|c|c|c|c|c|c|}
\hline Author & $\begin{array}{c}\text { Dose of } \\
\text { Radiation* } \\
\text { to } \\
\text { Lumbar Cord }\end{array}$ & $\begin{array}{c}\text { Interval } \\
\text { to } \\
\text { Neuropathy } \\
\text { (months) }\end{array}$ & $\begin{array}{c}\text { Survival } \\
\text { after } \\
\text { Neuropathy } \\
\text { (years) }\end{array}$ & Current & Clinical Status \\
\hline \multirow{15}{*}{$\begin{array}{l}\text { Maier et al. } \\
\quad \text { (1969) }\end{array}$} & 4,299 & 64 & 13 & Alive. & Unilateral leg paralysis. \\
\hline & 3,510 & 27 & 13 & Alive. & Right leg paralysis, left foot drop. \\
\hline & 4,810 & 15 & 16 & Alive. & Right leg paralysis. \\
\hline & 4,148 & 7 & 3 & Alive. & Incomplete bilateral leg paresis. \\
\hline & 4,587 & 156 & 6 & Alive. & Incomplete bilateral leg paresis. \\
\hline & 4,246 & 12 & 2 & Dead. & Bilateral foot drop. \\
\hline & 3,569 & 12 & 21 & Alive. & Limping gait, palsy. \\
\hline & 4,850 & 13 & 21 & Alive. & Paraplegic. \\
\hline & 4,420 & 12 & 5 & Dead. & Bilateral foot drop. \\
\hline & 3,520 & 12 & 14 & Alive. & Bilateral foot drop. \\
\hline & 4,800 & 6 & $2 \frac{1}{2}$ & Dead. & Bilateral foot drop, palsy right leg. \\
\hline & 5,680 & 12 & 3 & Dead. & Paralysis right leg. \\
\hline & 3,650 & 9 & 5 & Alive. & Bilateral leg weakness and muscular atrophy. \\
\hline & 5,310 & 4 & $1^{1 / 2}$ & Dead. & Paraplegic. \\
\hline & 5,400 & 12 & 13 & Alive. & Bilateral leg weakness and muscular atrophy. \\
\hline \multirow{5}{*}{$\begin{array}{l}\text { Klaua } \\
\qquad(1974)\end{array}$} & 3,000 & 1 & $1 / 4$ & Dead. & Plexus lesion left side. \\
\hline & 3,000 & 14 & - & Dead. & $\begin{array}{l}\text { Sensory disturbance both legs followed by weakness } \\
\text { of right leg. Root lesion L4 left. }\end{array}$ \\
\hline & 1,700 & 2 & 2 & Alive. & $\begin{array}{l}\text { Sensory disturbance left leg followed by weakness of } \\
\text { left leg. }\end{array}$ \\
\hline & 2,400 & 3 & 4 & Alive. & $\begin{array}{l}\text { Progressive paraparesis with loss of reflexes } \\
\text { and sensory loss. }\end{array}$ \\
\hline & - & 7 & - & Alive. & Femoral neuropathy right side. \\
\hline \multirow[t]{2}{*}{ Present } & $\begin{array}{l}6,750 \\
\quad \text { (tumor dose) }\end{array}$ & 48 & 9 & Alive. & Paraparesis with areflexia sensory loss. \\
\hline & $\begin{array}{l}6,760 \text { (left } \\
\text { pelvic wall) }\end{array}$ & 6 & 9 & Alive. & $\begin{array}{l}\text { Paraparesis with areflexia, greater on left side. } \\
\text { Sensory loss. }\end{array}$ \\
\hline and & $\begin{array}{l}5,900 \text { (right } \\
\text { pelvic wall) }\end{array}$ & & & & \\
\hline
\end{tabular}

* Presuming a lumbo-sacral site of injury, the dose estimated for the lumbar cord should be increased an average of $6.5 \%$.

patients, symptoms began within one year and in six of these within six months. However, the appearance of neurological abnormalities may be greatly delayed. One patient first developed symptoms after four years, one after five years and one after 15 years. Survival following neurological complications is frequently prolonged, a reflection no doubt of the treatable nature of the underlying cancer (cervix, testis, and bladder) and the young age of most patients. Because of this extended survival, the morbidity of radiation induced neuropathy assumes considerable clinical importance.

The clinical features of radiation induced lumbo-sacral neuropathy are rather constant. Lower motor neuron weakness of the legs occurs. This is sometimes confined to one leg (six patients). Most often both legs are affected although in many cases asymmetrical involvement is apparent. The muscle stretch reflexes are lost or reduced. Muscle wasting and sometimes muscle fasciculations are seen. Sensory loss, except in Maier's patients (1969), has been prominent. Clinical disturbance of sphincter function has not been observed. Progression of disability may extend for months or years either in insidious or, less often, step-wise fashion.

Lumbo-sacral radiculopathy is a rare complication following radiation of the abdominal cavity. Two patients are described and the findings in 20 previously reported cases are summarized. It is possible that this condition is more common than the frequency of reported cases suggests. The widely-held view that peripheral nerve is highly resistant to the effects of ionizing radiation must be reconsidered in the light of experimental work cited here (Cavanagh, 1968). Indeed, an animal model closely resembling these patients has been produced (Bradley, 1977).

In considering the tolerance of nervous tissue to radiation of the abdominal cavity, dosage to the lumbo-sacral plexus rather than the lumbar spinal cord should be estimated. 


\section{REFERENCES}

BATAINI, J. P., ENNUYER, A., PINCET, P., CLOSSEIN, N. A. (1974). Treatment of Supra-glottic Cancer by Radical High Dose Radiotherapy. Cancer 33: 1253-1262.

BRADLEY, W. G., FEWDINGS, J. D., CUMMING, W. J. K., and HARRISON R. M. (1977). Delayed Myeloradiculopathy Produced by Spinal X-jrradiation in the Rat. J. of the Neurol. Sciences 31: 63-82.

CAVANAGH, J. B. (1968). Effects of $X$-irradiation on the Proliferation of Cells in Peripheral Nerve During Wallerian Degeneration in the Rat. Br. J. Radiol. 41: 275-281.

CAVANAGH, J. B. (1968). Prior $X$-irradiation and the Cellular Response to Nerve Crush: Duration of Effect. Experimental Neurology 22: 253-258.

CHENG VINCENT, S. T. and SCHULZ, MILFORD D. (1975). Unilateral Hypoglossal Nerve Atrophy as a Late Complica- tion of Radiation Therapy and Head and Neck Carcinoma: A Report of Four Cases and a Review of the Literature on Peripheral and Cranial Nerve Damages after Radiation Therapy. Cancer 35: 1537-1544.

FRIEDMAN, M. (1954). Calculated Risks of Radiation Injury of Normal Tissue in the Treatment of Cancer of the Testis. Proc. Second National Cancer Conf. 1: 390-400.

GREENFIELD, Capt. Maurice and STARK, Maj. Fred (1948). Post Irradiation Neuropathy. Am. J. of Roentgenol. and Rad. Therapy 60: 617-622.

INNES, J. R. and CARSTEIN, A., Brookhaven (1967). Symp. Biol. 14: 200.

KLAUA, M. (1974). Radiogenic Peripheral Neuropathies Following Telecobalt Radiation in Abdominal Cavity (Author's Transl.) Radiobiol. Radiother. (Berl) 15(4): 459-464.

LINDER, R. (1959), Fortschr, Röntgenstr. 90617.
MAIER, J. G., PERRY, R. H., SAYLOR, W., and SULAK, M. H. (1969). Radiation Myelitis of the Dorsolumbar Spinal Cord. Radiology 93: 195-160.

MARUYAMA, J., MYLREA, M. M., and LOGOTHETIS, J. (1967). Neuropathy Following Irradiation, An Unusual Late Complication of Radiotherapy. Am. J. Roentgenol. 101: 216-219.

SHUKOVSKY, L. J. and FLETCHER, G. H. (1972). Retinal and Optic Nerve Complications in a High Dose Irradiation Technique of Ethmoid Sinus and Nasal Cavity. Radiology 104: 629-634.

STOLL, B. A. and ANDREWS, J. T. (1966). Radiation-induced Peripheral Neuropathy. Brit. Med. J., 1: 834-837.

TODD, M. C. and MEREDITH, W. J. (1938). A Dosage System for Use in the Treatment of Cancer of the Uterine Cervix. Brit. J. Radiol. 11: 809-814. 